\title{
Development of High-Strength Bolt Material of Al-Mg-Si Alloy by ECAP and Various Aging Treatments*1
}

\author{
Tomoyasu Obata ${ }^{1, * 2}$, Yongpeng Tang ${ }^{1, * 3}$, Hideaki Iwaoka ${ }^{1}$, Shoichi Hirosawa ${ }^{1, * 4}$, \\ Keiki Mouri ${ }^{2}$ and Masahiko Shimoda ${ }^{2}$ \\ ${ }^{1}$ Department of Mechanical Engineering and Materials Science, Yokohama National University, Yokohama 240-8501, Japan \\ ${ }^{2}$ Saga Tekkohsho Co., Ltd., Fujisawa 251-0015, Japan
}

At present, the strength of most of Al-Mg-Si alloy bolts is not enough, and thus highly expected to be increased, for example, to $>500 \mathrm{MPa}$ in ultimate tensile strength (UTS). In this study, mechanical strength of A6056 Al-Mg-Si alloy was aimed at improving, without diminishing the elongation, by combined application of equal-channel angular pressing (ECAP) and various aging treatments. Multi-pass ECAP and pre-aging (PA) treatment at $373 \mathrm{~K}$ for $1.2 \mathrm{ks}$ was found to be effective in strengthening the bolt material subject to room-temperature storage followed by artificial aging. Especially, PA plus ECAP 2pass treatment exerted the biggest impact on the strength (i.e. 514 MPa in UTS) with a reasonable elongation to fracture (i.e. 16\%). Such a high strength and good ductility exceeds minimum requirement for aluminum-made bolts registered in JIS B1057, and thus the developed PA-ECAP 2pass specimen can be utilized potentially as a high-strength bolt material. [doi:10.2320/matertrans.L-M2019825]

(Received February 28, 2019; Accepted April 2, 2019; Published June 7, 2019)

Keywords: Al-Mg-Si, ECAP, aging treatment, high-strength bolt, mechanical properties

\section{Introduction}

In recent years, $\mathrm{CO}_{2}$ emission regulation has been imposed on automobiles to prevent global warming, and thus automobile manufactures eagerly deal with the problem by improving efficiency of internal-combustion engines, by developing new power sources and by replacing conventional materials with lighter weight aluminum or magnesium alloys. In such a trend, materials of bolts which fasten automobile components are also paid attention, and a demand for aluminum-made bolts is remarkably increasing. This is because galvanic corrosion caused by the difference between standard electrode potentials occurs if aluminum or magnesium components are fastened by conventional steel bolts. The application of aluminum-made bolts can solve this corrosion problem ${ }^{1)}$ in addition to a further reduction of weight of automobiles. However, ultimate tensile strength (UTS) of conventional corrosion-resistant and formable Al$\mathrm{Mg}-\mathrm{Si}$ alloy bolts is about $320 \mathrm{MPa}$ (Table $1^{2)}$ ), and thus the range of application is quite limited, resulting in plastic region tightening disallowing the reuse of bolts. Therefore, if further strengthening can be achieved, elastic region tightening becomes possible, enabling not only to reuse the bolts but also to simplify working procedure of fastening. Recently, it was reported that forging workability of a relatively high-strength A6056 alloy can be improved with $420 \mathrm{MPa}$ in UTS by reexamining the conditions of casting and wire drawing. ${ }^{3)}$ However, strengthening is still in demand, therefore new methods such as severe plastic deformation have been attempted.

Equal-Channel Angular Pressing (ECAP) ${ }^{4-6)}$ is one of severe plastic deformation methods to obtain ultrafine grains at submicrometer or nanometer scale. A rod-shaped specimen

\footnotetext{
${ }^{* 1}$ This Paper was Originally Published in Japanese in J. JILM 68 (2018) $65-72$.

${ }^{* 2}$ Graduate Student, Yokohama National University

*3Present address: Kyushu University, Fukuoka 819-0395, Japan

${ }^{* 4}$ Corresponding author, E-mail: hirosawa@ynu.ac.jp
}

Table 1 Minimum requirement of mechanical properties for aluminummade bolts. Six alloys registered in JIS B10572) are compared.

\begin{tabular}{l|c|c|c|c}
\hline \hline Symbol & Alloy & $\begin{array}{c}\text { UTS } \\
(\mathrm{MPa})\end{array}$ & $\begin{array}{c}0.2 \% \mathrm{YS} \\
(\mathrm{MPa})\end{array}$ & $\begin{array}{c}\text { Elongation } \\
(\%)\end{array}$ \\
\hline AL1 & A5052 & $250-270^{*}$ & $180-230^{*}$ & $3-4$ \\
AL2 & A5056 & $280-310^{*}$ & $200-205^{*}$ & 6 \\
AL3 & A6061 & $310-320^{*}$ & $250-260^{*}$ & $7-10$ \\
AL4 & A2024 & $380-420^{*}$ & $260-290^{*}$ & $6-10$ \\
AL5 & A7N01 & 460 & 380 & 7 \\
AL6 & A7075 & 510 & 440 & 7 \\
\hline
\end{tabular}

*Depends on bolt size

is pushed into a die with a bent channel, and is subjected to shear deformation without changing the cross-sectional shape. It is possible to introduce a large amount of strain by repeating this process; i.e. by increasing the number of passes. Hockauf et al. ${ }^{7)}$ developed an A6056 alloy material with $\sim 450 \mathrm{MPa}$ in UTS by combined application of ECAP 2pass and aging treatment at $473 \mathrm{~K}$. Jin et al. ${ }^{8,9)}$ also succeeded in producing high-strength bolts of A6061-T6 alloy with $>460 \mathrm{MPa}$ in UTS by means of a newly developed and continuously repeatable spring-loaded ECAP. Therefore, it seems that the development of bolt materials with $>500 \mathrm{MPa}$ in UTS will be possible if both of ECAP and aging treatments are appropriately applied to $\mathrm{Al}-\mathrm{Mg}-\mathrm{Si}$ alloys.

In general, $\mathrm{Al}-\mathrm{Mg}-\mathrm{Si}$ alloys are utilized as structural components because of their good age-hardenability, but it is well known that if stored at room temperature (RT) before artificial aging, negative effect of two-step aging degrades the age-hardenability. ${ }^{10)}$ Pre-aging (PA) before RT storage can overcome such a negative effect of two-step aging, ${ }^{11)}$ and thus is expected to similarly work for $\mathrm{Al}-\mathrm{Mg}-\mathrm{Si}$ alloy bolts because their manufacturing process includes RT storage.

Therefore, the purpose of this study is to increase the mechanical strength of an A6056 Al-Mg-Si alloy, without 
Table 2 Chemical composition of the investigated A6056 Al-Mg-Si alloy (mass\%)

\begin{tabular}{c|c|c|c|c|c|c|c|c}
\hline \hline $\mathrm{Mg}$ & $\mathrm{Si}$ & $\mathrm{Cu}$ & $\mathrm{Fe}$ & $\mathrm{Mn}$ & $\mathrm{Zn}$ & $\mathrm{Cr}$ & $\mathrm{Ti}+\mathrm{Zr}$ & $\mathrm{Al}$ \\
\hline 0.88 & 1.02 & 0.71 & 0.16 & 0.58 & 0.17 & 0.03 & 0.15 & $\mathrm{Bal}$. \\
\hline
\end{tabular}

diminishing the elongation, for developing a high-strength bolt material through grain refinement strengthening by ECAP and precipitation strengthening by various aging treatments including PA.

\section{Experimental Procedure}

Cu-added A6056 Al-Mg-Si alloy with a chemical composition in Table 2 was investigated in this study. Rodshaped specimens with a diameter of $7.9 \mathrm{~mm}$ and a length of $45 \mathrm{~mm}$ were fabricated by swaging and cutting. The conventional manufacturing process of aluminum-made bolts consists of cold forging (screw head forming), solid solution treatment, water quenching (WQ), natural aging (RT storage), artificial aging and thread rolling. In this study, however, the specimens subject to processes excluding forging and thread rolling were referred to as the conventionally processed (CP) specimen. The schematic representation of the thermomechanical procedure of the CP specimen is shown in Fig. 1(a), in which commercially adopted conditions of natural and artificial aging are depicted as at RT for $86.4 \mathrm{ks}$ and at $448 \mathrm{~K}$ for $28.8 \mathrm{ks}$, respectively. The ECAP, PA and PA-ECAP specimens were fabricated by 1, 2 or 4 passes of ECAP within $7.2 \mathrm{ks}$ after WQ (Fig. 1(b)), by pre-aging at $373 \mathrm{~K}$ for $1.2 \mathrm{ks}$ immediately after WQ (Fig. 1(c)) and by combined application of PA and ECAP (Fig. 1(d)), followed by artificial aging at 373,408 or $448 \mathrm{~K}$. It can be considered that there is no influence of timing of ECAP on mechanical properties of the ECAP and PA-ECAP specimens because the hardness of the two specimens does not change until $7.2 \mathrm{ks}$ of RT storage after WQ, and until $24 \mathrm{~h}$ of RT storage after ECAP.

The utilized die for ECAP possesses a L-shaped bending channel with a channel angle of $\Phi=90^{\circ}$, an outer-corner angle of $\Psi=30^{\circ}$ and a diameter of $8 \mathrm{~mm}$. The amount of shear strain $\varepsilon_{N}$ after ECAP $N$ pass is given by eq. (1). ${ }^{12)}$

$$
\varepsilon_{N}=N\left[\frac{2 \cot \left(\frac{\Phi}{2}+\frac{\Psi}{2}\right)+\Psi \operatorname{cosec}\left(\frac{\Phi}{2}+\frac{\Psi}{2}\right)}{\sqrt{3}}\right]
$$

The extrusion rate was set at $0.067 \mathrm{mms}^{-1}$ and the specimen was rotated by $180^{\circ}$ for each pass (Route $\mathrm{C}^{4)}$ ) because introduced strain after ECAP 2pass is more homogeneous and symmetrical than without rotation or Route $\mathrm{Bc}$, in which the specimen is rotated by $90^{\circ}$ for each pass.

Vickers hardness test, tensile test, transmission electron microscopy (TEM) observation and differential scanning calorimetry (DSC) measurement were conducted for the specimens subject to various thermomechanical procedures. The age-hardenability of each specimen was measured by a Vickers hardness tester (Matsuzawa MMT-X1) with a load of $4.9 \mathrm{~N}$ for a dwelling time of $15 \mathrm{~s}$. The hardness was determined as an average value of five tested points out of seven ones by excluding the maximum and minimum values. The cross-section of rod-shaped specimens perpendicular to their longitudinal direction was tested for the ECAP and PA-ECAP specimens.

Tensile test was performed using a universal testing machine (Instron MODEL 4487) with an initial strain rate of $2.8 \times 10^{-3} \mathrm{~s}^{-1}$ at RT. The tensile test samples possess a dumbbell shape with a parallel length of $18 \mathrm{~mm}$ and a (a) $\mathrm{CP}$

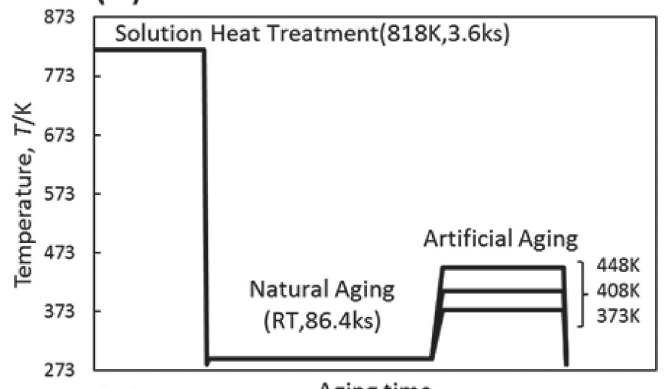

(c)PA

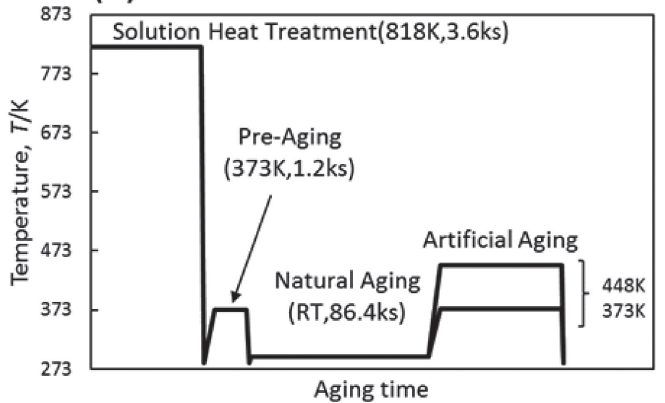

(b)ECAP

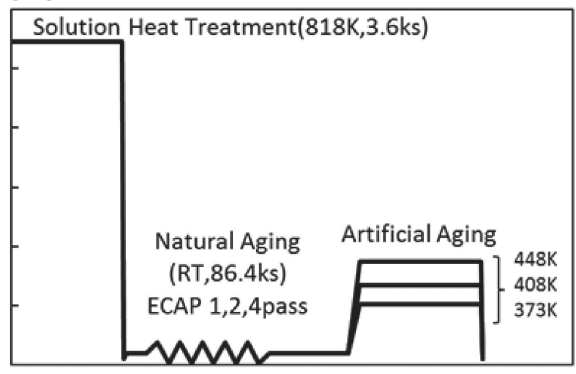

(d) PA-ECAP Aging time

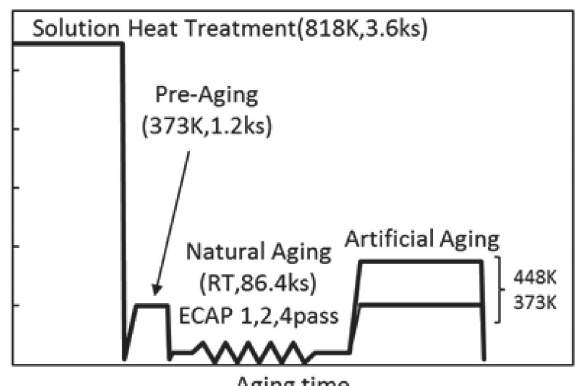

Aging time

Fig. 1 Schematic representation of the applied thermomechanical procedures to (a) conventionally processed (CP), (b) ECAP, (c) pre-aged (PA) and (d) PA-ECAP specimens. 

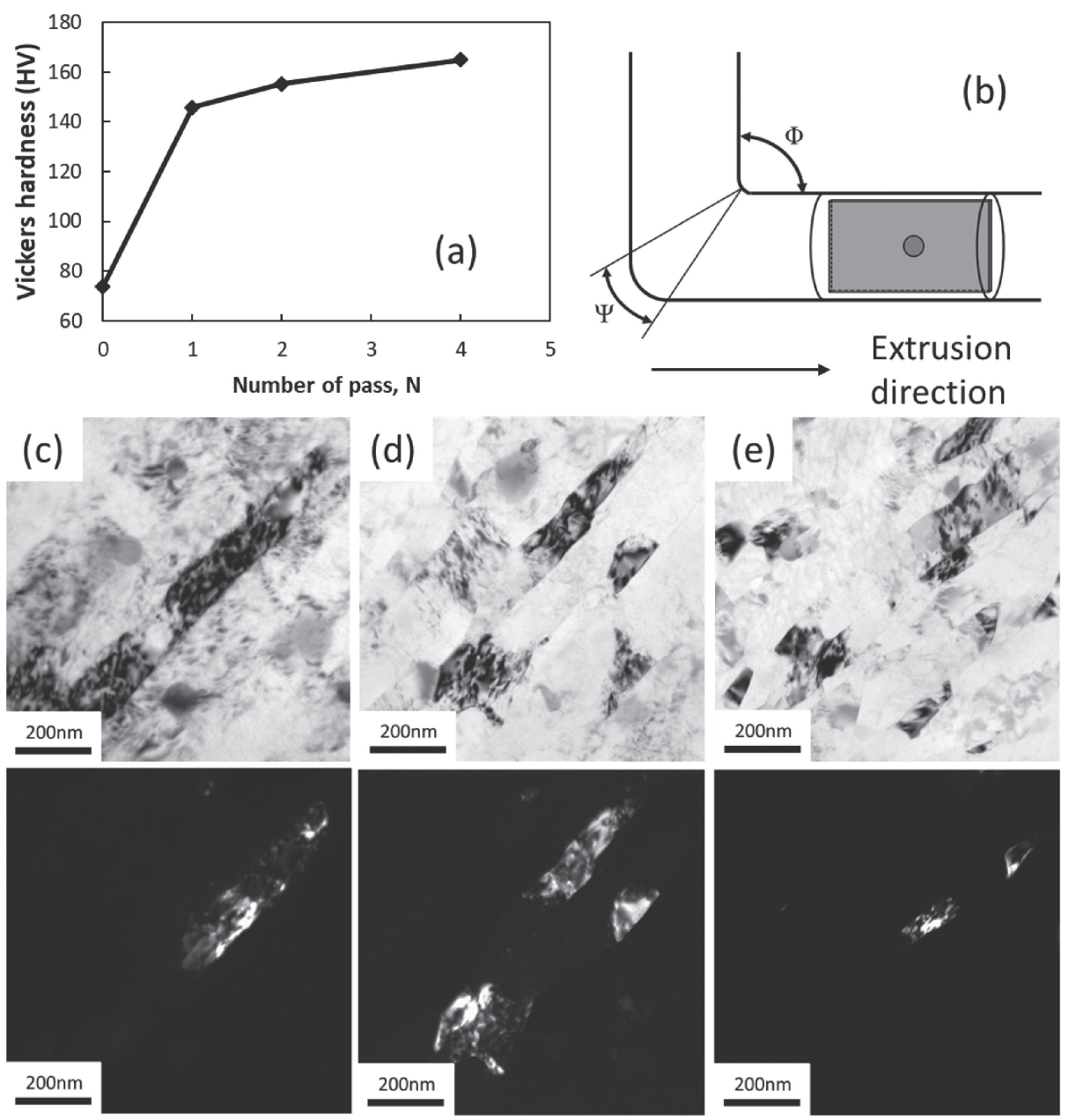

Fig. 2 Attained hardness (a) and the corresponding TEM microstructures of the (c) ECAP 1pass, (d) ECAP 2pass and (e) ECAP 4pass specimens. The TEM specimens were prepared from disk-shaped thin films after ECAP as shown in (b).

diameter of $3 \mathrm{~mm}$. After threaded at grip parts, two punch marks with an interval of $15 \mathrm{~mm}$ were made at parallel part, and then measured again after tensile test to quantify the change of the interval with a profile projector. In case that the interval cannot be measured with the profile projector, a caliper was utilized instead.

The foils for TEM observation were punched out from the center of the rod-shaped ECAP and PA-ECAP specimens (Fig. 2(b)), and then thinned by a twin-jet electropolishing unit (Struers Tenupol-5) with methyl nitrate (nitric acid:methanol $=85: 15$ ) cooled at $253 \mathrm{~K}$. Bright- and dark-field images were observed using a JEM-2100F microscope at an accelerating voltage of $200 \mathrm{kV}$.

Disc-shaped samples for DSC measurement were cut from the rod-shaped specimens with a weight of $36 \mathrm{mg}$. ULVAC Riko DSC-RL was utilized to measure heat flux during heating at a heating rate of $0.17 \mathrm{Ks}^{-1}$ with a reference counterpart of high-purity aluminum of 99.99 mass $\%$.

\section{Results and Discussion}

\subsection{Improvement of strength by ECAP}

Figure 2(a) shows the change in Vickers hardness by ECAP 1, 2 and 4passes (i.e. $\varepsilon_{1}=1.02, \varepsilon_{2}=2.03, \varepsilon_{4}=4.06$ ). The attained hardness increased from HV74 of the ECAP 0pass specimen to HV146 (i.e. $\triangle \mathrm{HV} 72$ ) by ECAP 1pass,
HV155 (i.e. $\triangle \mathrm{HV} 81$ ) by ECAP 2pass and HV165 (i.e. $\triangle$ HV91) by ECAP 4pass, respectively. This is because a reduction in grain size has occurred as illustrated in the corresponding TEM microstructures (Fig. 2(c)-(e)). For example, the thickness of grains elongated to $45^{\circ}$ from the extrusion direction ${ }^{4)}$ was decreased from $\sim 122 \mathrm{~nm}$ (ECAP 1pass) to $\sim 90 \mathrm{~nm}$ (ECAP 4pass), suggesting that grain refinement strengthening is activated with increasing the amount of strain introduced by ECAP (The thickness of grains was measured by the so-called line intercept method). The contribution of dislocation strengthening was assumed to be equivalent in each specimen because quantitative data on dislocation densities was not obtained in this study.

Figure 3(a) shows the changes in Vickers hardness during artificial aging at $448 \mathrm{~K}$ for the CP, ECAP 1, 2, and 4pass specimens. Although the increment in hardness was decreased from $\sim \triangle H V 65$ (CP) to $\sim \triangle H V 14$ (ECAP 1pass) or $\sim \Delta$ HV9 (ECAP 2pass), the hardness of the ECAP 1 and 2pass specimens was increased by artificial aging, but the hardness of the ECAP 4pass specimen did not increase at all at $448 \mathrm{~K}$ (Fig. 3(b)). Such a suppressed age-hardenability is due to coarsely and sparsely formed grain boundary precipitates of the stable $\beta$ phase as illustrated in Fig. 4. Note that both of the promoted diffusion of solute atoms along grain boundaries and the decreased activation energy required for the heterogeneous nucleation ${ }^{13)}$ are attributed 

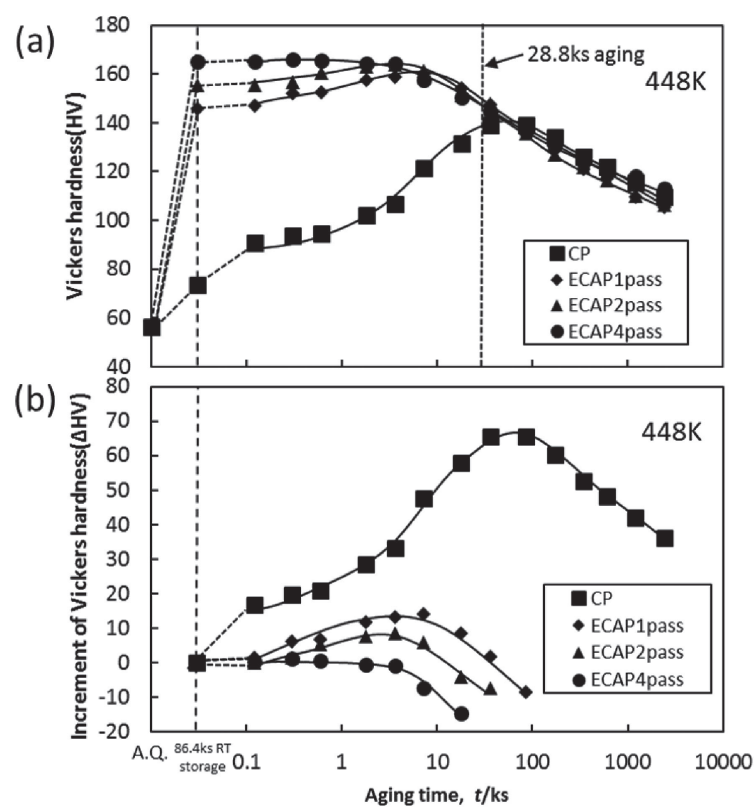

Fig. 3 Changes in (a) Vickers hardness and (b) increment of Vickers hardness during artificial aging at $448 \mathrm{~K}$ for the CP and ECAP 1, 2 and 4pass specimens.

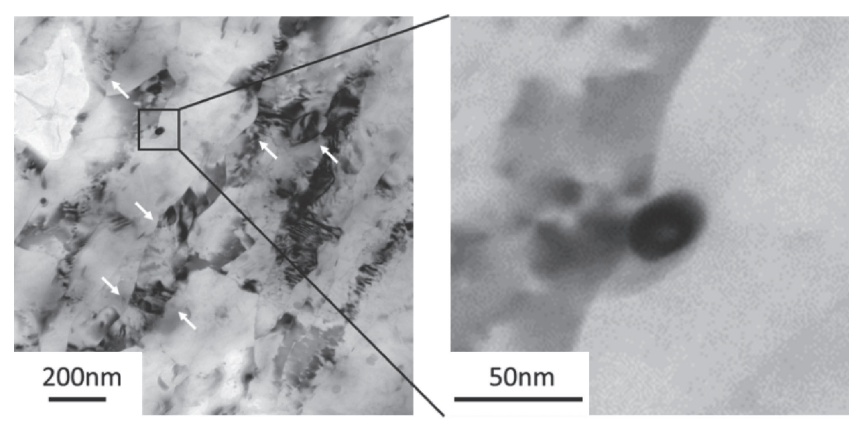

Fig. 4 TEM microstructures of the ECAP 2pass specimen after aged at $448 \mathrm{~K}$ for $1.8 \mathrm{ks}$. The stable $\beta$ phase is heterogeneously precipitated at grain boundaries as shown by arrows. to such a unfavorable formation of $\beta$, resulting in the suppressed formation of transgranular precipitates of the strengthening $\beta^{\prime \prime}$ phase. Therefore, it was found that concurrent strengthening by grain refinement and artificial aging is hardly achieved at a conventional aging temperature of $448 \mathrm{~K}$.

Figure 5 shows the changes in Vickers hardness during artificial aging at 373,408 and $448 \mathrm{~K}$ for the CP, ECAP 1,2 and 4 pass specimens. Although the age-hardening rate was decreased, both of the increment in hardness and the attained hardness increased with decreasing aging temperature. Therefore, based on the authors' proposal on concurrent strengthening by grain refinement and artificial aging, ${ }^{14)}$ the lowering of aging temperature was confirmed again to be effective even for the ECAP specimens of A6056 alloy utilized in this study.

\subsection{Improvement of strength by pre-aging}

Figure 6(a) shows the changes in Vickers hardness during artificial aging at $448 \mathrm{~K}$ for the $\mathrm{CP}, \mathrm{WQ}$ and PA specimens. The WQ specimen was subjected to artificial aging immediately after water quenching without RT storage. The hardness of the CP specimen after artificial aging for $28.8 \mathrm{ks}$ (HV134) was smaller than that of the WQ specimen (HV144), and the age-hardening rate up to $28.8 \mathrm{ks}$ was also decreased in the CP specimen. This result suggests that the negative effect of two-step aging is exerted on the agehardenability of the investigated A6056 alloy. On the other hand, the PA specimen subject to pre-aging at $373 \mathrm{~K}$ for $1.2 \mathrm{ks}$ recovered the suppressed age-hardening rate even after RT storage for $86.4 \mathrm{ks}$, and achieved almost the same attained hardness (HV143) as that of the WQ specimen (HV144). Therefore, it was confirmed that the application of pre-aging can increase the attained hardness (i.e. improvement of HV9), or shorten the commercially adopted aging time (i.e. from $28.8 \mathrm{ks}$ to $\sim 10 \mathrm{ks}$ at which the equivalent hardness of HV134
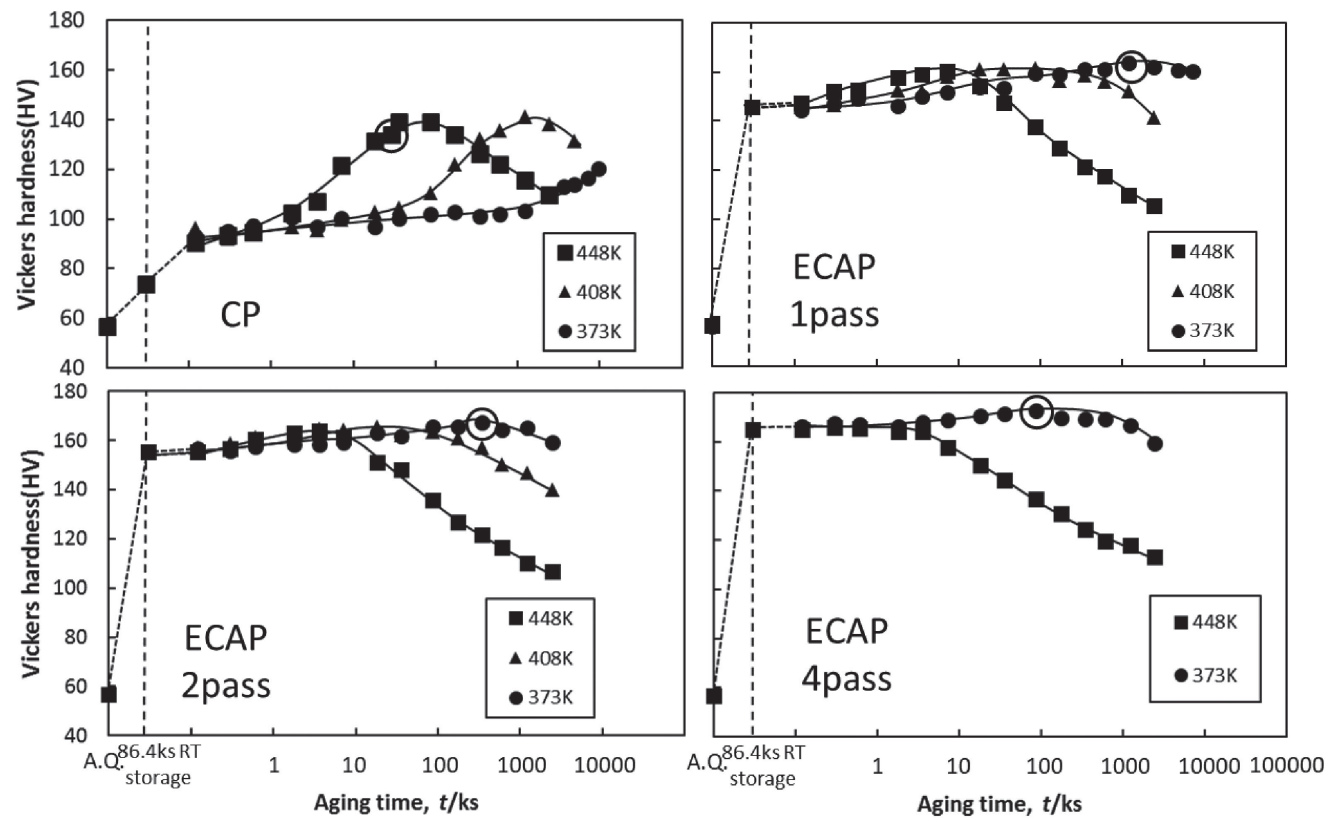

Fig. 5 Change in Vickers hardness during artificial aging at 373 to $448 \mathrm{~K}$ for the CP and ECAP 1, 2 and 4 pass specimens. The aging conditions applied to tensile test specimens in Fig. 11 are indicated by circles. 

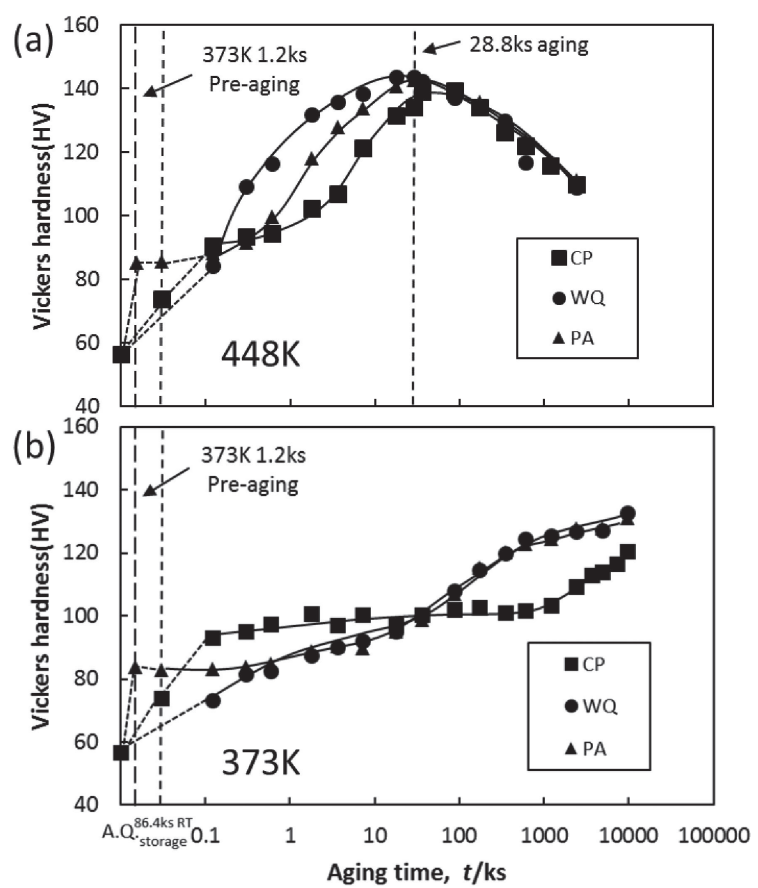

Fig. 6 Changes in Vickers hardness during artificial aging at (a) $448 \mathrm{~K}$ and (b) $373 \mathrm{~K}$ for the $\mathrm{CP}$, WQ (Immediately aged after water-quenched without natural aging) and PA specimens.

to the conventional A6056 alloy bolts can be obtained) of the $\mathrm{CP}$ specimen. The similar recovery of age-hardening rate of the $\mathrm{CP}$ specimen was also observed at $373 \mathrm{~K}$ in Fig. 6(b), where the PA specimen shows similar agehardening behavior as the WQ specimen. Therefore, preaging was found to be effective even at lower artificial aging temperatures.

\subsection{Improvement of strength by pre-aging and ECAP}

Figure 7(a), (b) shows the changes in hardness during artificial aging at $373 \mathrm{~K}$ for the ECAP 1, 2pass and PA-ECAP 1,2 pass specimens. By the application of pre-aging before ECAP, the hardness of the PA-ECAP specimen became higher than that of the ECAP specimen, but the increment in hardness was monotonously decreased from $\triangle \mathrm{HV} 10$ (ECAP 1pass) to $\triangle \mathrm{HV} 4$ (ECAP 2pass) or $\triangle \mathrm{HV} 2$ (ECAP 4pass, but no data is shown in the paper). This decrease of increment in hardness is probably because nanoclusters formed during pre-aging were decomposed and re-dissolved into the matrix by accumulative dislocations introduced by the subsequent ECAP, resulting in the gradual decrease in contribution of nanoclusters with increasing the number of ECAP passes. Note that the difference in hardness between WQ and PA specimens (i.e. $\Delta$ HV29. See Fig. 6(a), (b)) is due to the formation of nanoclusters, and thus if the amount of nanoclusters is decreased by ECAP, the increase in hardness from ECAP specimens must have been decreased to $\triangle \mathrm{HV} 10$, $\triangle \mathrm{HV} 4, \triangle \mathrm{HV} 2$ and so on.

On the other hand, the age-hardenability of the PA-ECAP 1pass specimen $(\triangle \mathrm{HV} 14)$ was lower than that of the ECAP 1pass specimen $(\Delta \mathrm{HV} 18)$ as illustrated in Fig. $7(\mathrm{c})$. This suggests that the amount of precipitates formed during artificial aging is smaller than that of the ECAP 1pass specimen because a part of nanoclusters formed during preaging survive even after ECAP 1pass, resulting in the suppressed age-hardenability during artificial aging of the PA-ECAP 1pass specimen. However, the age-hardenability of the PA-ECAP 2pass specimen ( $\triangle \mathrm{HV} 14)$ was higher than that of ECAP 2pass specimen $(\triangle \mathrm{HV} 12)$ as illustrated in Fig. 7(d). This reverse phenomenon may be because most of nanoclusters formed during pre-aging are decomposed and re-dissolved into the matrix by ECAP 2pass, and thus a larger (a)

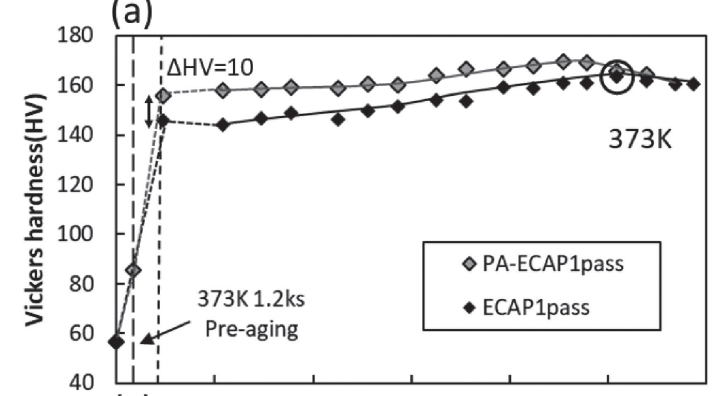
(c)

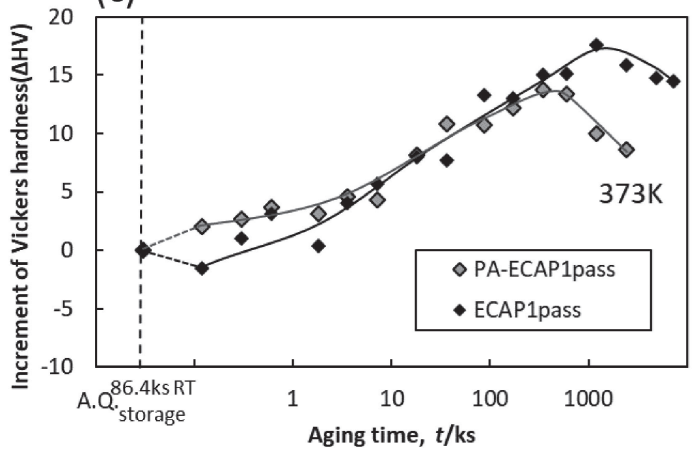

(b)

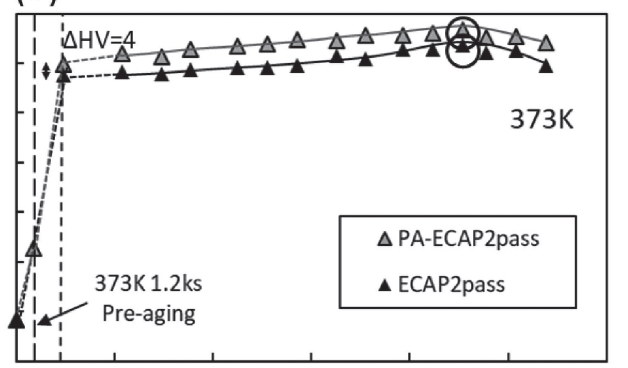

(d)

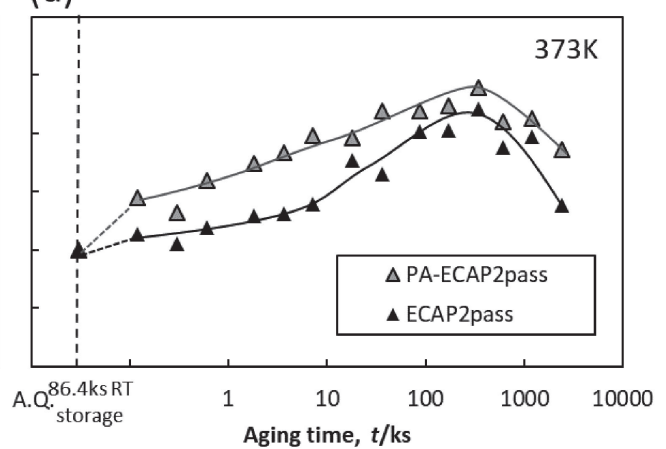

Fig. 7 Changes in $(a, b)$ Vickers hardness and $(c, d)$ increment of Vickers hardness during artificial aging at $373 \mathrm{~K}$ for the ECAP 1 pass and PA-ECAP 1 pass specimens $(a, c)$, or for the ECAP 2pass and PA-ECAP 2pass specimens (b, d). The aging conditions applied to tensile test specimens in Fig. 11 are indicated by circles. 


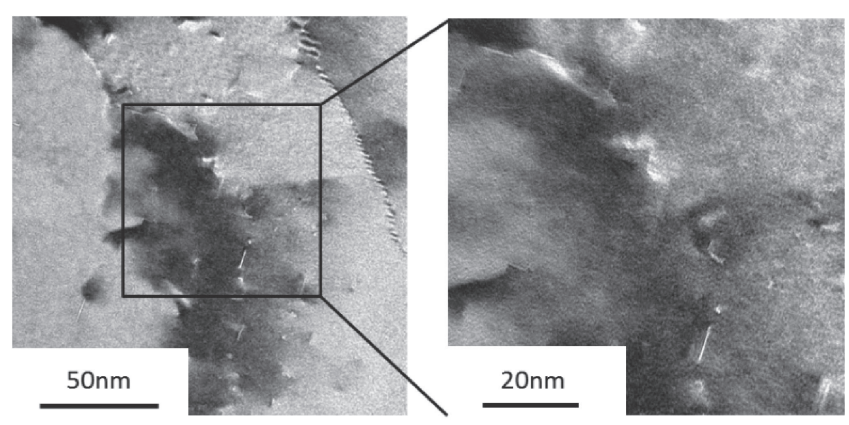

Fig. 8 TEM microstructures of the PA-ECAP 2pass specimen after peakaged at $373 \mathrm{~K}$ for $345.6 \mathrm{ks}$. Strain contrast arising from nanoclusters is visible within the matrix, together with the needle-shaped $\beta^{\prime \prime}$ phase at dislocations and grain boundaries.

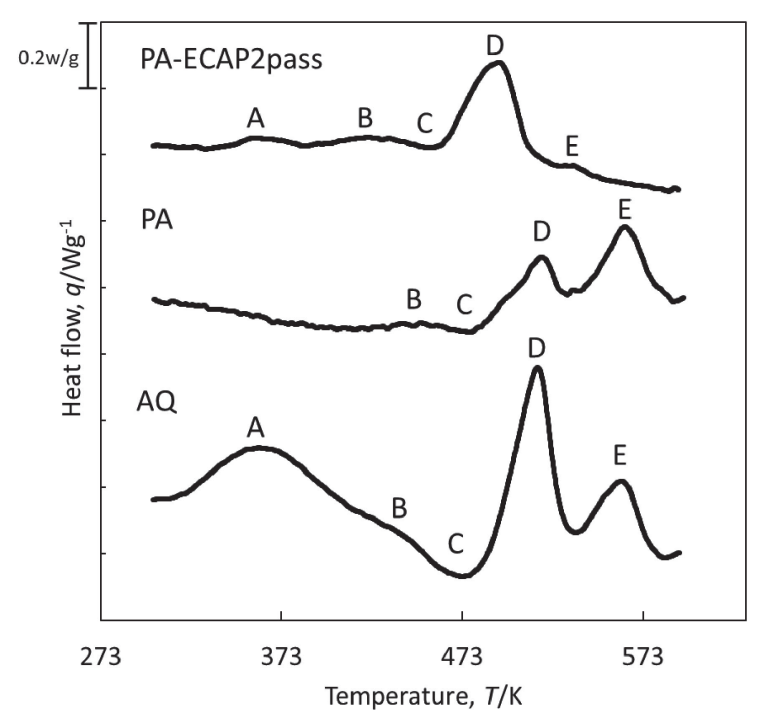

Fig. 9 DSC curves of the AQ (Immediately heated after water-quenched without natural aging), PA and PA-ECAP 2pass specimens.

amount of precipitates can be formed during artificial aging, responsible for the larger increment in hardness of the PAECAP 2pass specimen. As the corresponding TEM microstructures (Fig. 8) cannot prove the existence of such nanoclusters and/or precipitates, the validity of the above mechanism was evaluated by DSC measurement as described below.

Figure 9 shows the DSC curves of the as-quenched (AQ), PA and PA-ECAP 2pass specimens. According to the results of previous studies, ${ }^{15-20)}$ the four exothermic peaks A, B, D and $\mathrm{E}$ can be regarded as the formations of nanoclusters, GP zones or $\mathrm{Cu}$-containing clusters, the $\beta^{\prime \prime}$ phase, and the $\beta^{\prime}$ and $\mathrm{Q}^{\prime}$ phases (i.e. precursor of the quaternary Q- $\mathrm{Al}_{5} \mathrm{Cu}_{2} \mathrm{Mg}_{8} \mathrm{Si}_{6}$ phase), respectively, whereas the endothermic peak $\mathrm{C}$ around $473 \mathrm{~K}$ as the dissolution of nanoclusters. It is clearly seen in Fig. 9 that the peak A indicating the formation of nanoclusters disappeared in the PA specimen, but appeared again in the PA-ECAP 2pass specimen. This suggests that nanoclusters have been formed by pre-aging, but decomposed and re-dissolved into the matrix by ECAP 2pass, as predicted by the above proposed mechanism. Further investigation using three-dimensional atom probe is in progress to clarify the effect of accumulative dislocations

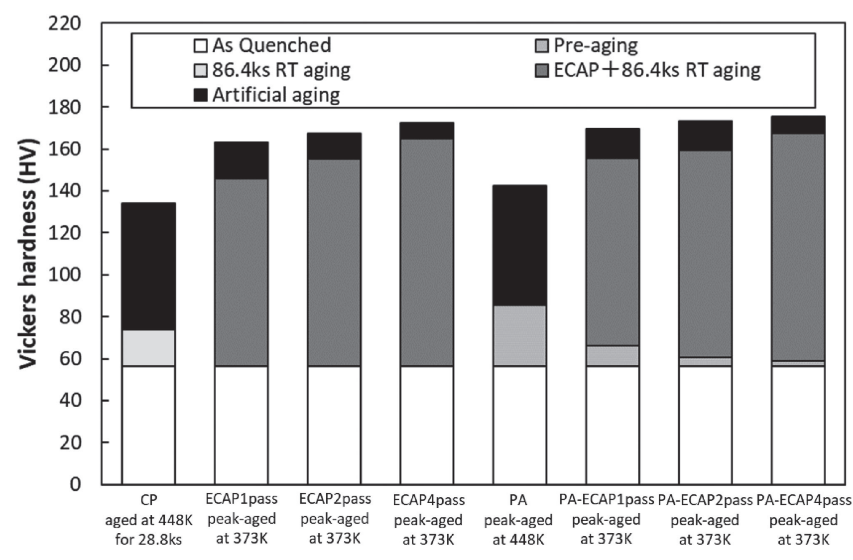

Fig. 10 Attained hardness of the investigated specimens with various ECAP and aging treatments. The contribution of each thermodynamic procedure to hardness increase is also indicated.

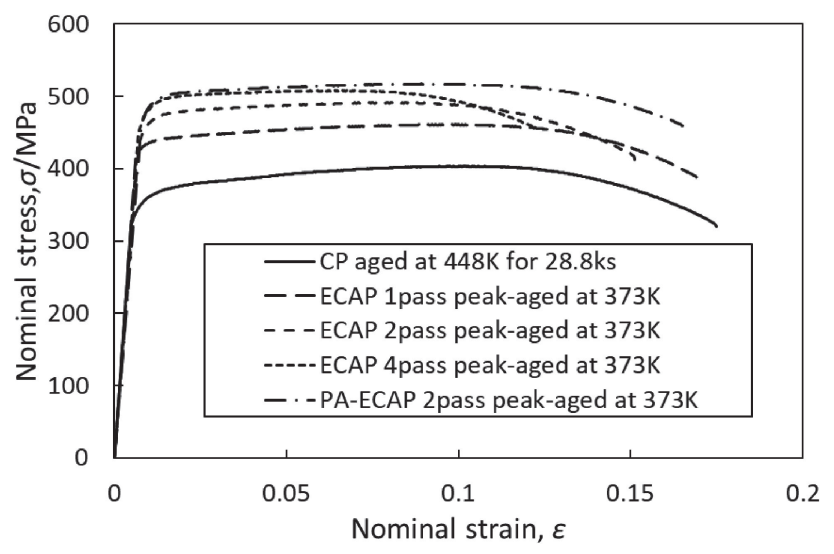

Fig. 11 Stress-strain curves of the newly developed bolt material with various ECAP and aging treatments. The curve of the CP (aged at $448 \mathrm{~K}$ for $28.8 \mathrm{ks}$ ) specimen is also shown for comparison.

introduced by ECAP on the distribution of nanoclusters formed during pre-aging.

\subsection{Mechanical properties of developed bolt material}

Figure 10 shows the contribution of each thermodynamic procedure to the attained hardness of the developed bolt material in this study. The attained hardness of every ECAP specimen was quite higher than that of the CP specimen aged at $448 \mathrm{~K}$ for $28.8 \mathrm{ks}$ (i.e. HV134 as a standard hardness of the conventional A6056 alloy bolt). Especially, the attained hardness of the PA-ECAP 2pass and ECAP 4pass specimens successfully exceeded HV170 owing to the greater contribution of ECAP.

Figure 11 shows the results of tensile test for the developed bolt material. The estimated UTS of the ECAP 1, 2 and 4pass specimens; i.e. 462, 492 and 509 MPa, was higher than that of the CP specimen (405 MPa), but the elongation to failure was monotonically decreased from $17 \%$ of the CP specimen to $12 \%$ of the ECAP 4pass specimen (Table 3). However, UTS and elongation to failure of the PA-ECAP 2pass specimen were $514 \mathrm{MPa}$ and $16 \%$, suggesting that combined application of pre-aging and ECAP 2pass can achieve not only a high strength comparable to that of the ECAP 4pass specimen, but also sufficient ductility through a "mild" process of ECAP 2pass. 
Table 3 The obtained tensile properties after peak-aged at $373 \mathrm{~K}$ for the newly developed bolt material with various ECAP and aging treatments. The values of the CP (aged at $448 \mathrm{~K}$ for $28.8 \mathrm{ks}$ ) specimen are also listed for comparison.

\begin{tabular}{l|c|c|c}
\hline \hline & $\begin{array}{c}\text { UTS } \\
(\mathrm{MPa})\end{array}$ & $\begin{array}{c}0.2 \% \mathrm{YS} \\
(\mathrm{MPa})\end{array}$ & $\begin{array}{c}\text { Elongation } \\
(\%)\end{array}$ \\
\hline CP (aged at 448 K for 28.8ks) & 405 & 352 & 17 \\
ECAP 1pass & 462 & 432 & 16 \\
ECAP 2pass & 492 & 465 & 14 \\
ECAP 4pass & 509 & 493 & 12 \\
PA-ECAP 2pass & 514 & 491 & 16 \\
\hline
\end{tabular}

Figure 12 shows strength-ductility balance of the developed bolt material in this study. For comparison, six registered alloys for aluminum-made bolts (Table 12) and previously reported $\mathrm{Al}-\mathrm{Mg}-\mathrm{Si}$ alloys subject to ECAP $^{7-9,21-23)}$ were also plotted. The PA-ECAP 2pass specimen was found to possess quite high strength comparable to that of A7075 alloy with much improved ductility. Therefore, combined application of pre-aging and ECAP has proved that the strength of A6056 alloy can be increased to $>500 \mathrm{MPa}$ (i.e. $514 \mathrm{MPa}$ in UTS) with a reasonable elongation to fracture (i.e. 16\%). Such a high strength and good ductility exceeds minimum requirement for aluminum-made bolts registered in JIS B1057, and thus the developed PA-ECAP 2pass specimen can be utilized potentially as a high-strength bolt material.

\section{Conclusions}

The age-hardening behavior of A6056 Al-Mg-Si alloy subject to pre-aging and equal-channel angular pressing (ECAP) was investigated, and the possibility to utilize as a high-strength bolt material was estimated based on the mechanical properties including Vickers hardness, ultimate tensile strength (UTS) and elongation to failure. The obtained results were summarized below.

(1) Although the increment in hardness was drastically decreased, the hardness of the ECAP 1 and 2pass specimens increased during artificial aging at $448 \mathrm{~K}$, but the ECAP 4pass specimen did not show any agehardenability at $488 \mathrm{~K}$. On the other hand, both of the increment in hardness and the attained hardness have been improved at $373 \mathrm{~K}$, suggesting that concurrent strengthening by grain refinement and artificial aging can be achieved if artificial aging temperature is lowered.

(2) The pre-aging at $373 \mathrm{~K}$ for $1.2 \mathrm{ks}$ could overcome the negative effect of two-step aging appeared in the CP specimen. Therefore, the application of pre-aging was proved to be effective not only in increasing the attained hardness but also in shortening the commercially adopted aging time to $\sim 10 \mathrm{ks}$ at which the equivalent hardness to the conventional A6056 alloy bolts can be obtained.

(3) The PA-ECAP 2pass specimen possessed a good strength-ductility balance of $514 \mathrm{MPa}$ in UTS and

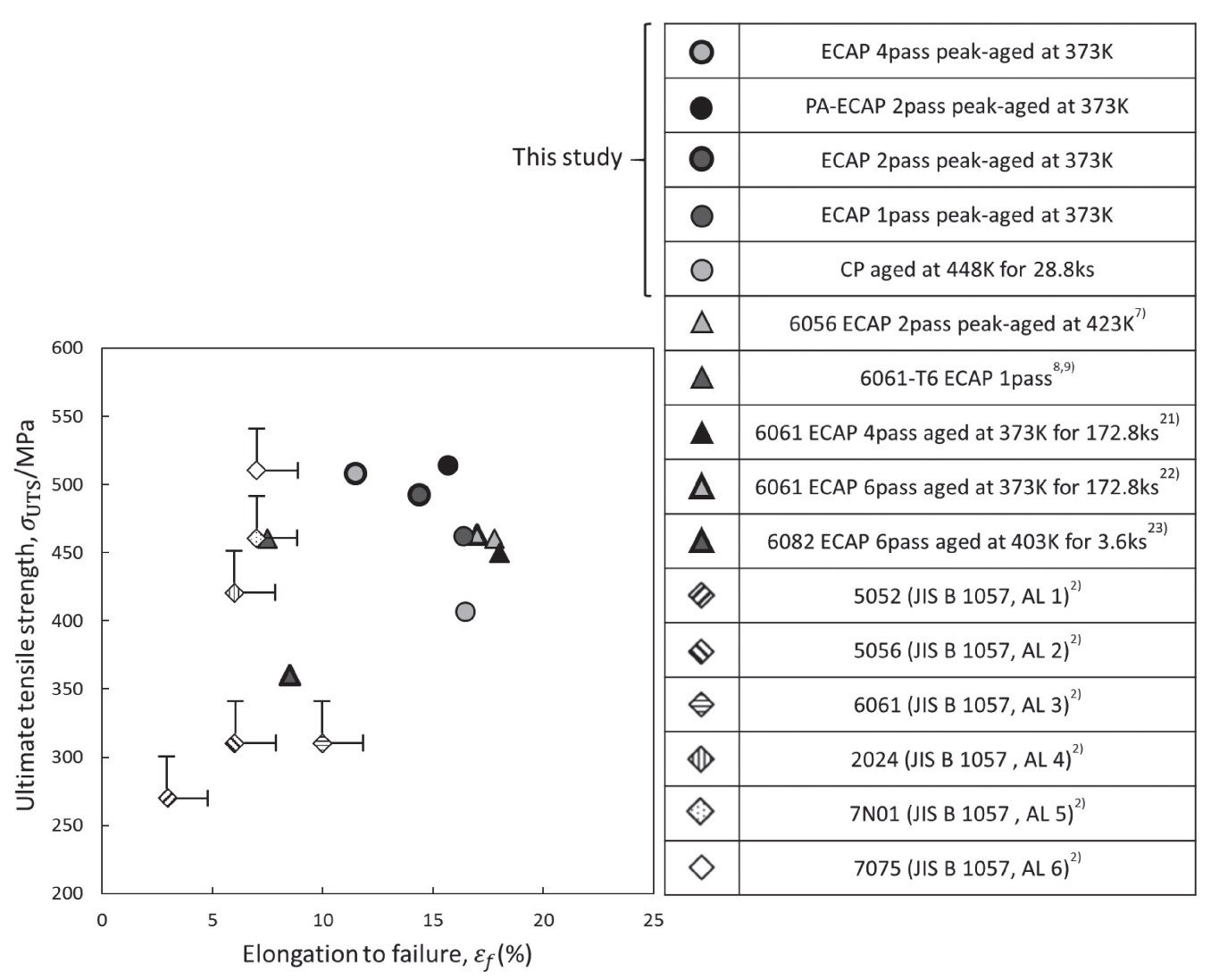

Fig. 12 Strength-ductility balance of the newly developed bolt material with various ECAP and aging treatments. The mechanical properties of previously reported ECAP-processed specimens ${ }^{7-9,21-23)}$ and registered alloys for aluminum-made bolts $\left(\mathrm{JIS}\right.$ B10572) are $^{2}$ also plotted for comparison. 
$16 \%$ in elongation to fracture. These values exceed minimum requirement for aluminum-made bolts registered in JIS B1057, and thus the developed specimen can be utilized potentially as a high-strength bolt material.

\section{Acknowledgments}

A part of this study was supported by the JST (Japan Science and Technology Agency) under collaborative research based on industrial demand "Heterogeneous structure control: Towards innovative development of metallic structural materials". A deepest acknowledgment is expressed to emeritus professor Takao Yakou, Yokohama National University, for his provision of the utilized ECAP die.

\section{REFERENCES}

1) Japan Aluminum Association: Aluminum Handbook (7th edition), (2007) pp. 58-81.

2) Mechanical properties of non-ferrous metal screw parts: Japan Industrial Standard JIS B 1057, issued by Japan Standards Association, (2001) 1-19.

3) I. Iwayama, T. Kwabara, Y. Nakai, Y. Takaki, S. Kitamura and H. Saito: SEI Technical Review 183 (2013) 78-82.

4) Y. Iwahashi, Z. Horita, M. Nemoto and T.G. Langdon: Acta Mater. 46 (1998) 3317-3331.

5) K. Oishi, K. Kaneko and Z. Horita: Materia Japan 41 (2002) 422 426.
6) A. Azushima, R. Kopp, A. Korhonen, D.Y. Yang, F. Micari, G.D. Lahoti, P. Groche, J. Yanagimoto, N. Tsuji, A. Rosochowski and A. Yanagida: CRIP Ann. Manuf. Technol. 57 (2008) 716-735.

7) K. Hockauf, L.W. Meyer, M. Hockauf and T. Halle: J. Mater. Sci. 45 (2010) 4754-4760.

8) Y.G. Jin, H.M. Beak, Y.-T. Im and B.C. Jeon: Mater. Sci. Eng. A 530 (2011) 462-468.

9) Y.G. Jin, H.M. Beak, S.K. Hwang, Y.-T. Im and B.C. Jeon: J. Mater. Process. Technol. 212 (2012) 848-855.

10) T. Sato: Light Metals 56 (2006) 592-601.

11) T. Muramatsu: Furukawa Electric Review 114 (2004) 42-47.

12) Y. Iwahashi, J. Wang, Z. Horita and M. Nemoto: Scr. Mater. 35 (1996) 143-146.

13) T. Hirata and S. Matsuo: Met. Mater. 36 (1972) 1159-1163.

14) S. Hirosawa, Y. Tang, Z. Horita, S. Lee, K. Matsuda and D. Terada: Adv. Mater. Res. 1135 (2016) 161-166.

15) H. Hatta, S. Matsuda, H. Tanaka and H. Yoshida: Light Metals 59 (2009) 439-443.

16) A. Serizawa, S. Hirosawa and T. Sato: Mater. Sci. Forum 519-521 (2006) 245-250.

17) A. Serizawa, S. Hirosawa and T. Sato: Metall. Mater. Trans. A 39 (2008) 243-251.

18) S. Esmaeili, X. Wang, D.J. Lloyd and W.J. Poole: Metall. Mater. Trans. A 34 (2003) 751-763.

19) W.F. Miao and D.E. Laughlin: Metall. Mater. Trans. A 31 (2000) 361371.

20) H. Suzuki, M. Kanno, Y. Shiraishi and K. Hanawa: Light Metals 29 (1979) 575-581.

21) J.K. Kim, H.G. Jeong, S.I. Hong, Y.S. Kim and W.J. Kim: Scr. Mater. 45 (2001) 901-907.

22) W.J. Kim, J.K. Kim, T.Y. Park, S.I. Hong, D.I. Kim and J.D. Lee: Metall. Mater. Trans. A 33 (2002) 3155-3164.

23) G. Angella, P. Bassani, A. Tuissi and M. Vedani: Mater. Trans. 45 (2004) 2282-2287. 